\title{
Improving the effective efficiency of a spark ignition engine through the use of a fully independent valve control system
}

ARTICLE INFO

Received: 26 July 2021

Revised: 16 August 2021

Accepted: 23 August 2021

Available online: 30 August 2021
The article presents theoretical research of the proposed system of fully independent valve control (FIVC) of the SI engine. The analysis included controlling the movement of the intake valves, which results in adjusting the mass of the fresh charge to the current engine load, as well as the movement of the exhaust valves, where the main aim is to keep the rest of the exhaust gas in the cylinder, i.e. implementation of internal EGR. The open theoretical Seiliger-Sabathe cycle with the classic throttle regulation of load is the reference cycle for assessment of benefits and study of the effectiveness of obtaining work as a result of application of the FIVC system. A comparative analysis of the effectiveness of application of the proposed system was carried out based on the selected quantities: fuel dose, cycle work, relative work of charge exchange and cycle efficiency. The use of the FIVC to regulate the SI engine load makes it possible to eliminate the throttle and thus reduce the charge exchange work, especially in the partial load range. And this then leads to an increase in internal and effective work, which in turn results in an increase in the effective energy efficiency of an engine operation.

Key words: SI engine, theoretical cycle, charge exchange, engine efficiency, independent valve control

This is an open access article under the CC BY license (http://creativecommons.org/licenses/BY/4.0/)

\section{Introduction - the importance of the charge exchange process in an ICE}

The energy conversion process taking place in an internal combustion engine can be characterized by the effective energy efficiency $\eta_{\mathrm{e}}$, defined as:

$$
\eta_{\mathrm{e}}=\frac{\mathrm{N}_{\mathrm{e}}}{\dot{\mathrm{m}}_{\mathrm{p}} \mathrm{H}_{\mathrm{u}}}
$$

where $\dot{\mathrm{m}}_{\mathrm{p}}$ - mass flux of consumed fuel, $\mathrm{H}_{\mathrm{u}}-$ calorific value of fuel.

The theoretical cycle of the ICE consists of physical processes that reflect the idealized course of the real engine processes. The ratio of the theoretical cycle power $\mathrm{N}_{\mathrm{o}}$ to the fuel chemical energy flux expresses the energy efficiency of the theoretical cycle:

$$
\eta_{\mathrm{o}}=\frac{\mathrm{N}_{\mathrm{o}}}{\dot{\mathrm{m}}_{\mathrm{p}} \mathrm{H}_{\mathrm{u}}}
$$

Based on the real cycle of the engine, the internal power $\mathrm{N}_{\mathrm{i}}$ is determined and then the internal efficiency, defined as:

$$
\eta_{\mathrm{i}}=\frac{\mathrm{N}_{\mathrm{i}}}{\dot{\mathrm{m}}_{\mathrm{p}} \mathrm{H}_{\mathrm{u}}}
$$

The perfection of the implementation of thermodynamic processes in an ICE is assessed by the rate of internal excellence $\xi_{\mathrm{i}}$, which expresses the ratio of the internal power $\mathrm{N}_{\mathrm{i}}$ of the engine to the power $\mathrm{N}_{\mathrm{o}}$ of the theoretical cycle:

$$
\xi_{\mathrm{i}}=\frac{\mathrm{N}_{\mathrm{i}}}{\mathrm{N}_{\mathrm{o}}}
$$

The mechanical friction losses and the power necessary to drive the engine auxiliary mechanisms are characterized by the rate of mechanical excellence $\xi_{\mathrm{m}}$, defined as the ratio of the effective power $\mathrm{N}_{\mathrm{e}}$ to the internal power $\mathrm{N}_{\mathrm{i}}$ :

$$
\xi_{\mathrm{m}}=\frac{\mathrm{N}_{\mathrm{e}}}{\mathrm{N}_{\mathrm{i}}}
$$

The effective energy efficiency $\eta_{\mathrm{e}}$ of an internal combustion engine can therefore be expressed as the product of the theoretical cycle efficiency $\eta_{\mathrm{o}}$ and the rates of excellence:

$$
\eta_{\mathrm{e}}=\eta_{\mathrm{o}} \xi_{\mathrm{i}} \xi_{\mathrm{m}}
$$

Formula (6) shows that due to changes in the theoretical cycle, leading to an increase in the value of its energy efficiency $\eta_{\mathrm{o}}$, it is possible to obtain an increase in the value of the effective energy efficiency $\eta_{\mathrm{e}}$ of the engine.

The operation of the car engine at the optimal point, due to the maximum, effective efficiency $\eta_{\mathrm{e}}$, occurs relatively rarely. For a spark ignition engine, this point of optimal operation is situated close to the external characteristic. In operation range far away from the optimal point, i.e. for partial loads, the effective energy efficiency $\eta_{\mathrm{e}}$ of the internal combustion engine is significantly lower than the maximum value.

Among the many reasons for the reduction of efficiency in the area of partial loads, two should be mentioned as significant:

- an increase in the work of charge exchange leading to a decrease in the rate $\xi_{\mathrm{i}}$ of internal excellence,

- an increase in the relative work of friction, related to the internal work, resulting in a decrease in the rate $\xi_{\mathrm{m}}$ of mechanical excellence.

Greater potential for improving the situation is associated with the reduction of losses in the process of charge exchange, which in turn will result in an increase in the rate of internal excellence, mainly in the field of partial loads. A significant reduction in charge exchange work in the SI engine can be achieved by eliminating the throttle by introducing independent valve control. 
Independent valves control (IVC) is one of the most promising technical solutions to solve the pumping losses problem in SI engines due to its potential in eliminating the throttle. In recent years, various kind of IVC systems have been developed, but only few has been successfully brought into the market, such as the Valvetronic, Valvematic and Multiair (UniAir) [5, 16, 19]. A considerable improvement in engine performance and fuel economy at partial load has been reported by using these systems [3, 13].

Many engine concerns are working on design solutions of valve trains in which the valve movement control will be completely independent. The most advanced works are on mechanisms in which the opening and closing of valves is performed using electromagnetic systems $[4,9,10,15]$.

Camless valve trains, in which the valve motion is completely independent of the piston motion, can improve the fuel economy by $20 \%$ or higher with no pumping loss for SI engines [17]. Optimizing the valve timing at all operating conditions results in a nearly flat torque characteristic with $10 \%$ increase in maximum torque and up to $50 \%$ at low torque [17].

Initial tests of a passenger car, according to the Japanese driving cycle (type 10-15), with an SI engine equipped with an electromagnetic valve actuator showed the possibility of reducing fuel consumption by approximately $7 \%$ compared to an engine with a conventional timing system [14]. These tests also showed an increase in torque by $20 \%$ in the range of low and medium engine loads. On the other hand, tests of the car, carried out according to the NEDC, with the SI engine also equipped with an electromagnetic valve control system, showed a reduction in fuel consumption of up to $19 \%$ [12]. An increase in torque of up to $20 \%$ in the low engine load range was also found.

Camless timing systems in internal combustion engines are also developed on the basis of an electrohydraulic drive $[11,20]$. The first car, produced in series since September 2009, to use an SI engine with the UniAir system characterized by full variable valve timing is the Alfa Romeo MiTo [8]. The drive unit used in this car is an turbocharged SI engine with a maximum power of $100 \mathrm{~kW}$. This engine uses an electrohydraulic system for independent control, but only the intake valves. The exhaust valves are controlled conventionally by means of a camshaft. The benefits of using the UniAir system are as follows [1, 7]:

- reduction of fuel consumption up to $10 \%$,

- power increase up to $10 \%$,

- increase of the torque up to $15 \%$ in the range of lower engine loads.

However, with the electro-hydraulic UniAir system, the maximum valve lift is reduced when the inlet valve is earlier closed. Electromagnetic motor valve drives do not have this disadvantage [2, 18].

A novelty in the presented solutions, which are the subject of the research, is the development and analysis of a system of fully independent control of valves, both inlet and exhaust. The task of the inlet valves will be to adjust the mass of the charge load to the required engine load. On the other hand, the independent movement of the exhaust valves will enable the controlled retention of the rest of the exhaust gas in the cylinder, i.e. the implementation of inter- nal exhaust gas recirculation. Thus, the aim of using fully independent valve control (FIVC) is to eliminate the throttle, the regulatory function of which is taken over by the valves, while maintaining quantitative control of the engine load.

\section{Basic features of the cycle}

A fully independent valve control (FIVC) system is achieved by combining the early inlet valve closing (EIVC) system $[6,21]$ with the early exhaust valve closing (EEVC) system [20]. The FIVC system enables the implementation of internal exhaust gas recirculation and full adjustment of the fuel dose. The theoretical open cycle of a piston internal combustion engine for a fully independent valve control system is shown in Fig. 1.

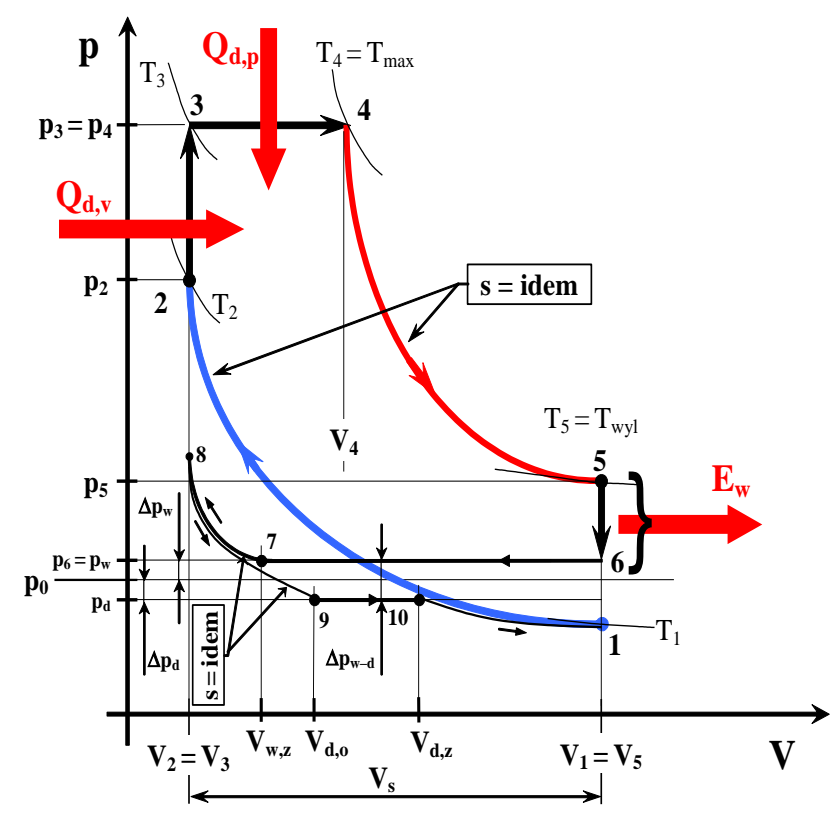

$\mathrm{p}_{\mathrm{d}}$ - pressure in the intake system $\quad \mathrm{p}_{\mathrm{w}}$ - pressure in the exhaust system $\mathrm{p}_{0}$ - ambient pressure

$\mathrm{V}_{\mathrm{s}}$ - cylinder displacement

Fig. 1. Open, ideal cycle for the system of fully independent valve control (FIVC)

The engine load regulation in the FIVC system is made using two independent control parameters:

- compression ratio of the recirculated exhaust gas $\varepsilon_{\mathrm{w}, \mathrm{Z}}$ :

$$
\varepsilon_{\mathrm{w}, \mathrm{z}}=\frac{\mathrm{V}_{\mathrm{w}, \mathrm{z}}}{\mathrm{V}_{2}}
$$

which is a parameter that regulates the mass of the recirculated exhaust gas $\mathrm{m}_{\mathrm{sr}}$,

- relative cylinder volume $\varepsilon_{\mathrm{d}, \mathrm{z}}$ at which the intake valve closes:

$$
\varepsilon_{\mathrm{d}, \mathrm{z}}=\frac{\mathrm{V}_{\mathrm{d}, \mathrm{z}}}{\mathrm{V}_{2}},
$$

which is a parameter that regulates the mass of fresh charge fed to the cylinder.

The values of the control parameters in relative terms, depending on the cycle work $\mathrm{L}_{\mathrm{o}}$, are shown in Fig. 2. The cycle work $\mathrm{L}_{\mathrm{o}}$ is related to the maximum work $\mathrm{L}_{\mathrm{o} \text {, max }}$ of the 
Seiliger-Sabathe open cycle. The dependence of the cycle work on the control parameters is linear, which is advantageous for regulatory reasons.

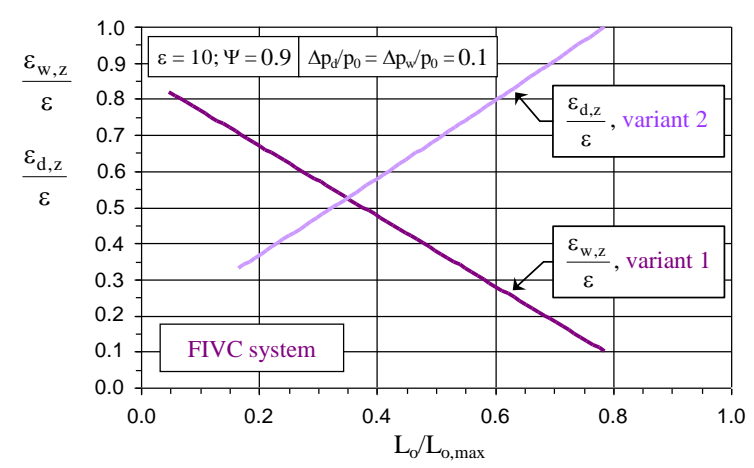

Fig. 2. Control parameters for the FIVC system versus cycle work for two boundary variants

The characteristics in Fig. 2 and in all other figures are presented for two limit variants of the analysed system:

- variant 1: for $\varepsilon_{\mathrm{d}, \mathrm{z}}=\varepsilon=\mathrm{idem}$,

then the control parameter is $\varepsilon_{\mathrm{w}, \mathrm{z}}=\mathrm{var}$,

- variant 2: for $\varepsilon_{\mathrm{w}, \mathrm{z}}=1=$ idem,

then the control parameter is $\varepsilon_{\mathrm{d}, \mathrm{z}}=$ var.

\section{Fuel dose}

The basic parameters deciding about the amount of fuel dose are (Fig. 1): $\mathrm{V}_{\mathrm{w}, \mathrm{z}}$ - cylinder volume when closing the exhaust valve, $\mathrm{V}_{\mathrm{d}, \mathrm{o}}$ - cylinder volume corresponding to the beginning of the inlet valve opening, $\mathrm{V}_{\mathrm{d}, \mathrm{z}}$ - cylinder volume when closing the inlet valve, $\Delta \mathrm{p}_{\mathrm{w}}$ - exhaust gas pressure drop in the exhaust system, $\Delta \mathrm{p}_{\mathrm{d}}$ - air pressure drop in the intake system, $\lambda$ - excess air ratio.

Assuming that $\lambda=$ idem, the fuel dose can be expressed as follows [20]:

$$
\mathrm{m}_{\mathrm{p}}=\mathrm{m}_{\mathrm{p}, 0} \frac{\mathrm{p}_{\mathrm{d}}}{\mathrm{p}_{0}} \frac{\mathrm{V}_{\mathrm{d}, \mathrm{z}}-\mathrm{V}_{\mathrm{d}, \mathrm{o}}}{\mathrm{V}_{1}-\mathrm{V}_{2}},
$$

where $\mathrm{m}_{\mathrm{p}, 0}$ - base amount of fuel dose, corresponding to the maximum mass of fresh charge delivered to the cylinder, $\mathrm{p}_{\mathrm{d}}$ - intake manifold pressure.

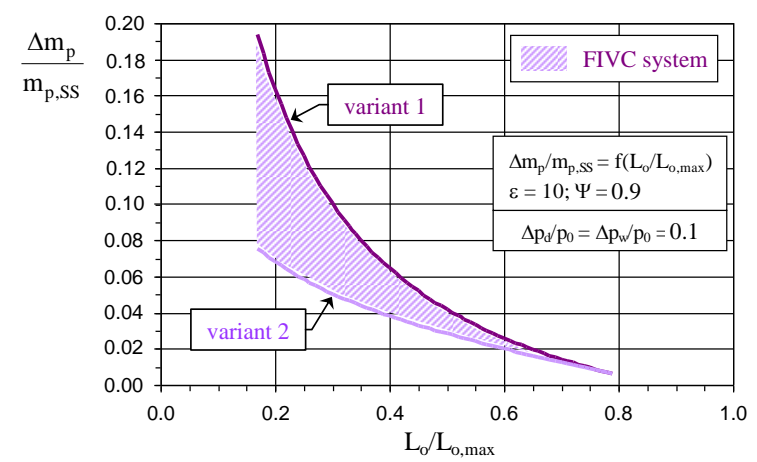

Fig. 3. Relative reduction of the fuel dose $\Delta \mathrm{m}_{\mathrm{p}} / \mathrm{m}_{\mathrm{p}, \mathrm{SS}}$ for the FIVC system compared with the classic throttle governing system, versus cycle work

The relative reduction of the fuel dose $\Delta \mathrm{m}_{\mathrm{p}} / \mathrm{m}_{\mathrm{p}, \mathrm{SS}}$ for the FIVC, compared to the system with classic throttle control, is shown in Fig. 3. The hatched area covers the full range of value changes of two independent engine load control pa- rameters $\varepsilon_{\mathrm{w}, \mathrm{z}}$ and $\varepsilon_{\mathrm{d}, \mathrm{z}}$. A reduction of the fuel dose in relation to the classical throttle control was found in the whole load range, and particularly significant (reaching up to $18 \%)$ in the low load area.

\section{Charge exchange work}

The work of charge exchange $\mathrm{L}_{\mathrm{w}}$ for the FIVC can be written as the sum of the components of the useful works:

$$
\mathrm{L}_{\mathrm{w}}=\mathrm{L}_{\mathrm{u}, 6-7}+\mathrm{L}_{\mathrm{u}, 7-8}+\mathrm{L}_{\mathrm{u}, 8-9}+\mathrm{L}_{\mathrm{u}, 9-10}
$$

The index $\mu$ of the relative charge exchange work is defined as the ratio of the charge exchange work $\mathrm{L}_{\mathrm{w}}$ (10) to the cycle work $\mathrm{L}_{\mathrm{o}}$ :

$$
\mu=\frac{\left|\mathrm{L}_{\mathrm{w}}\right|}{\mathrm{L}_{\mathrm{o}}}
$$

The work of charge exchange $\mathrm{L}_{\mathrm{w}}$ for the FIVC system is shown in Fig. 4. In this figure, for comparison, the work for the Seiliger-Sabathe open cycle is also presented. The course of the charge exchange work for the FIVC system is the opposite in terms of quality, compared to the system with classic throttle control (open Seiliger-Sabathe cycle). In the FIVC system, the absolute value of the charge exchange work decreases as the engine load is reduced, which is a significant advantage. As a result, the relative work of the charge exchange $\mu$ does not reach significant values in the range of low loads (Fig. 5).

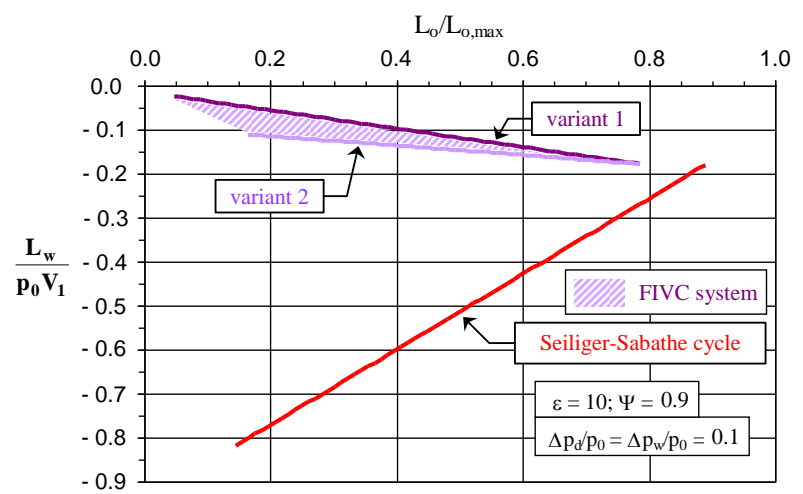

Fig. 4. Comparison of the charge exchange works $\mathrm{L}_{\mathrm{w}} /\left(\mathrm{p}_{0} \mathrm{~V}_{1}\right)$ for the FIVC system and Seilger-Sabathe cycle

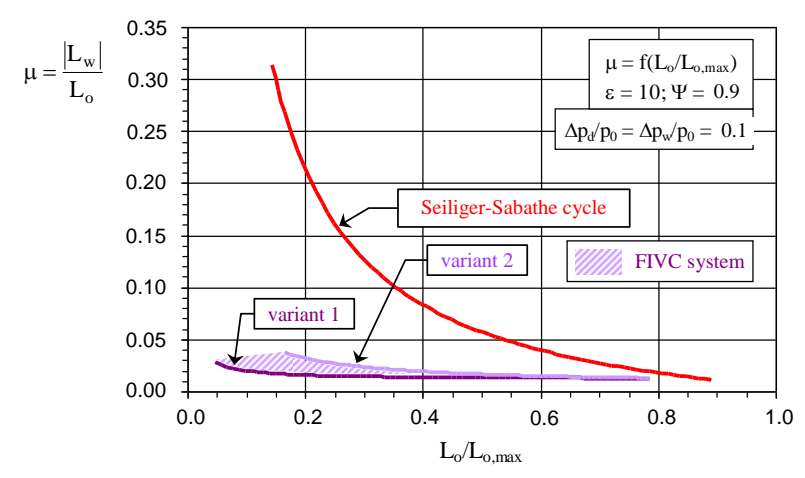

Fig. 5. Comparison of the relative charge exchange works $\mu$ for the FIVC system and Seilger-Sabathe cycle

For the FIVC system, the index $\mu$ does not exceed $4 \%$. Such low values of the relative work of charge exchange 
are the result of the elimination of the throttle from the intake system.

\section{Cycle efficiency}

In the energy aspect, an important parameter is the cycle efficiency $\eta_{\mathrm{o}}$. The efficiency of the theoretical cycle expresses the ratio of the work of the cycle $\mathrm{L}_{\mathrm{o}}$ to the total energy $Q_{d}$ fed into the cycle:

$$
\eta_{\mathrm{o}}=\frac{\mathrm{L}_{\mathrm{o}}}{\mathrm{Q}_{\mathrm{d}}}
$$

The efficiencies $\eta_{0}$ of the FIVC cycle and SeiligerSabathe cycle are shown in Fig. 6.

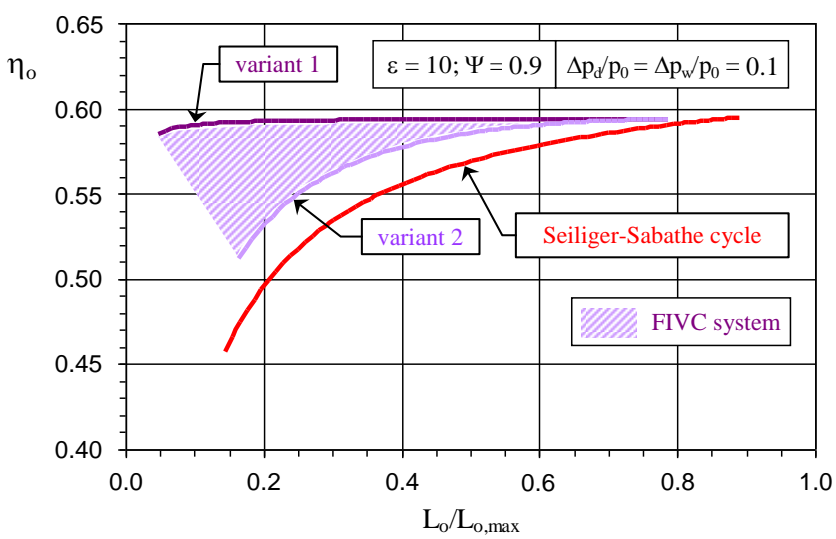

Fig. 6. Comparison of efficiencies $\eta_{\mathrm{o}}$ of the cycles for the FIVC system and Seilger-Sabathe cycle

The efficiencies $\eta_{\mathrm{o}}$ of the cycles for the FIVC are higher than the efficiency of the open theoretical Seiliger-Sabathe cycle. By increasing the value of the cycle efficiency $\eta_{0}$, it is possible to increase the value of the effective energy efficiency $\eta_{\mathrm{e}}$ of an engine. The highest efficiency is achieved by the cycle for the limit variant 1 . In the range of low loads, the cycle efficiency of the variant 1 is about 0.1 greater than the efficiency of the cycle with classic throttle control. Characteristic and advantageous for variant 1 is the flat course of the cycle efficiency over the entire range of the cycle work. Thus, this variant is most suitable for load regulation of a spark-ignition engine. The only limitation in this respect may be too high values of the exhaust gas recirculation rate, but only at the lowest values of the cycle work (Fig. 7).

\section{Parameters of the internal exhaust gas recircula- tion process}

The main parameters characterizing the process of internal exhaust gas recirculation are:

- exhaust gas recirculation rate $\alpha_{\mathrm{r}}$ :

$$
\alpha_{\mathrm{r}}=\frac{\mathrm{m}_{\mathrm{sr}}}{\mathrm{m}_{1}}, \quad 0 \leq \alpha_{\mathrm{r}}<1
$$

where $\mathrm{m}_{\mathrm{sr}}-$ mass of the recirculated exhaust gas (retained in the cylinder), $\mathrm{m}_{1}$ - total charge mass (charge mass at point 1 of the cycle);

- multiplicity of exhaust gas recirculation $\alpha_{\mathrm{k}}$ :

$$
\alpha_{\mathrm{k}}=\frac{\mathrm{m}_{\mathrm{sr}}}{\mathrm{m}_{\mathrm{m}}}, \quad \alpha_{\mathrm{k}}>0
$$

where $\mathrm{m}_{\mathrm{m}}$ - mass of the fresh charge (mixture) fed into the cylinder.

Taking into account the relationships connecting the masses appearing in definitions (13) and (14) and additionally that $\mathrm{m}_{1}=\mathrm{m}_{10}$, the above definitions can be written in the form:

$$
\alpha_{\mathrm{r}}=\frac{\mathrm{m}_{\mathrm{sr}}}{\mathrm{m}_{\mathrm{m}}+\mathrm{m}_{\mathrm{sr}}}, \quad \alpha_{\mathrm{k}}=\frac{\mathrm{m}_{\mathrm{sr}}}{\mathrm{m}_{1}-\mathrm{m}_{\mathrm{sr}}}
$$

and indicate the interdependence between the parameters $\alpha_{\mathrm{r}}$ and $\alpha_{\mathrm{k}}$ :

$$
\alpha_{r}=\frac{\alpha_{k}}{1+\alpha_{k}}, \quad \alpha_{k}=\frac{\alpha_{r}}{1-\alpha_{r}}
$$

The exhaust gas recirculation rate $\alpha_{\mathrm{r}}$ can also be expressed by the cycle parameters. Taking into account the dependencies between the relevant cycle parameters, the following is achieved [20]:

$$
\alpha_{\mathrm{r}}=\frac{1+\frac{\Delta \mathrm{p}_{\mathrm{w}}}{\mathrm{p}_{0}}}{1-\frac{\Delta \mathrm{p}_{\mathrm{d}}}{\mathrm{p}_{0}}} \frac{\varepsilon_{\mathrm{w}, \mathrm{z}}}{\varepsilon_{\mathrm{d}, \mathrm{z}}}\left(\frac{\varepsilon}{\varepsilon_{\mathrm{d}, \mathrm{z}}}\right)^{(\kappa-1)} \frac{\varphi^{-\kappa}}{\gamma} \frac{\mathrm{M}_{\mathrm{sr}}}{\mathrm{M}_{1}}
$$

Similarly, if formulas expressing the mass $\mathrm{m}_{\mathrm{sr}}$ of recirculated exhaust gas and the mass $\mathrm{m}_{\mathrm{m}}$ of the fresh mixture supplied are substituted in the definition (14) of the exhaust gas recirculation multiplicity $\alpha_{k}$, and the relationships between the relevant cycle parameters are taken into account, it is obtained [20]:

$\alpha_{\mathrm{k}}=\frac{1+\frac{\Delta \mathrm{p}_{\mathrm{w}}}{\mathrm{p}_{0}}}{1-\frac{\Delta \mathrm{p}_{\mathrm{d}}}{\mathrm{p}_{0}}} \frac{\varepsilon_{\mathrm{w}, \mathrm{z}}}{\varepsilon_{\mathrm{d}, \mathrm{z}}-\varepsilon_{\mathrm{d}, \mathrm{o}}} \frac{\frac{\varphi^{-\kappa}}{\gamma}\left(\frac{\varepsilon}{\varepsilon_{\mathrm{d}, \mathrm{z}}}\right)^{(\kappa-1)}}{1+\frac{\mathrm{p}_{\mathrm{w}}}{\mathrm{p}_{1}} \frac{\varepsilon_{\mathrm{w}, \mathrm{z}}}{\left(\varepsilon_{\mathrm{d}, \mathrm{z}}-\varepsilon_{\mathrm{d}, \mathrm{o}}\right)}\left[\left(\frac{\varepsilon_{\mathrm{w}, \mathrm{z}}}{\varepsilon_{\mathrm{d}, \mathrm{o}}}\right)^{(\kappa-1)}-\left(\frac{\varepsilon}{\varepsilon_{\mathrm{d}, \mathrm{z}}}\right)^{(\kappa-1)} \frac{\varphi^{-\kappa}}{\gamma}\right]} \frac{\mathrm{M}_{\mathrm{sr}}}{\mathrm{M}_{\mathrm{m}}}$

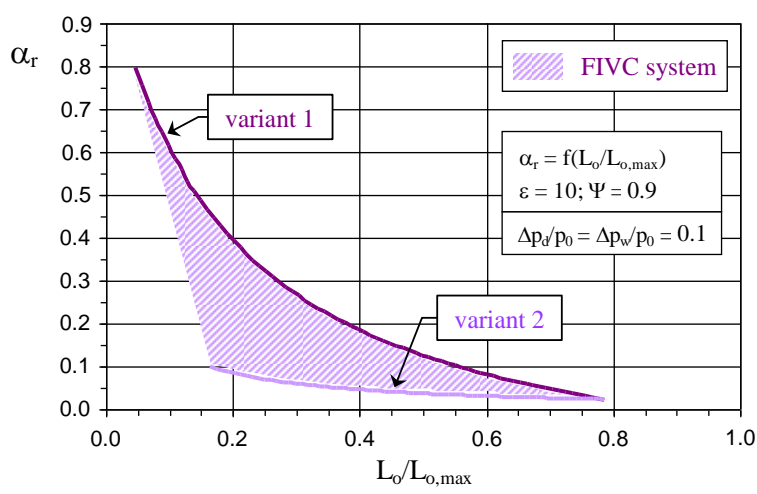

Fig. 7. Exhaust gas recirculation rate $\alpha_{\mathrm{r}}$ for the FIVC system versus cycle work

The exhaust gas recirculation rate $\alpha_{\mathrm{r}}$ and multiplicity the exhaust gas recirculation $\alpha_{\mathrm{k}}$ for the FIVC system, depending on the cycle work, are shown in Figs 7 and 8, respectively.

In the range of low loads, for the limit variant 1 of the load control, high values of the recirculation rate $\alpha_{\mathrm{r}}$ (up to $80 \%)$ are achieved, and the recirculation multiplicity $\alpha_{k}$ reaches 4 . These values may turn out to be too high due to 
the certainty of ignition, as well as the correctness of the fuel combustion process. Then, when using the FIVC system to regulate the load in the engine, the FIVC system in this area of the engine operation will not be available. The acceptable values of the recirculation rate and the exhaust gas recirculation multiplicity may be determined only through experimental tests.

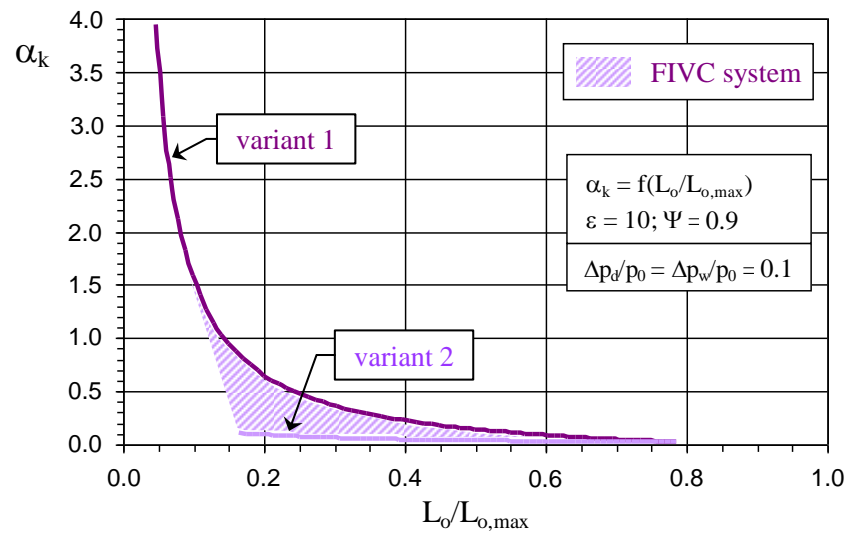

Fig. 8. Multiplicity of exhaust gas recirculation $\alpha_{\mathrm{k}}$ for the FIVC system versus cycle work

The ecological aspect of the application of the FIVC system should also be emphasized. Thanks to exhaust gas recirculation, the maximum combustion temperature is lowered, thereby reducing nitrogen oxide emissions. More- over, the heat flux (heat loss) to the cylinder walls is reduced.

\section{Conclusion}

The observed beneficial effects of the use of the fully independent valve control system are, first of all, the result of elimination of the throttle as an actuator for regulating the SI engine load, while maintaining quantitative load regulation. In the scope of regulation of filling and engine load, in the proposed system the valves take over the function of the throttle. It has been confirmed that one of the significant ways to improve the efficiency of SI engines, especially in terms of partial loads, is to reduce the work of charge exchange. The work of charge exchange for the analysed FIVC system is much smaller than the work of charge exchange for the classic throttle control (SeiligerSabathe cycle). For the FIVC system, the value of the relative charge exchange work does not exceed $4 \%$ over the entire load range. As a result, in the low load range, the efficiency of the FIVC cycle is increased by more than 10 percentage points compared to the Seiliger-Sabathe cycle.

For ecological reasons, it may also be beneficial to combine the proposed independent valve control system with other primary and secondary measures aimed at reducing emission of harmful substances.

\section{Acknowledgements}

This scientific work was supported by Faculty of Power and Environmental Engineering of the Silesian University of Technology within the statutory research.

\section{Nomenclature}

EIVC early inlet valve closing

EEVC early exhaust valve closing

FIVC fully independent valve control

ICE internal combustion engine

IVC independent valve control

L work

m mass

M molar mass

$\mathrm{N}$ power

NEDC New European Driving Cycle

$\mathrm{p} \quad$ pressure
Q heat

SI spark ignition

$\mathrm{T}$ temperature

$\mathrm{V}$ volume

$\alpha_{\mathrm{k}} \quad$ multiplicity of exhaust gas recirculation

$\alpha_{\mathrm{r}} \quad$ exhaust gas recirculation rate

$\varepsilon \quad$ compression ratio

$\lambda$ excess air ratio

$\eta \quad$ energy efficiency

$\mu \quad$ relative charge exchange work

$\Psi \quad$ heat distribution number

\section{Bibliography}

[1] BERNARD, L., FERRARI, A., MICELLI, D. et al. Electrohydraulic valve control with "Multiair" technology. MTZ Motortechnische Zeitschrift. 2009, 70, 4-10. https://doi.org/10.1007/BF03226988

[2] CHANG, S.C. Stability analysis, routes to chaos, and quenching chaos in electromechanical valve actuators. Mathematics and Computers in Simulation. 2020, 177, 140151. https://doi.org/10.1016/j.matcom.2020.04.021

[3] COPE, D., WRIGHT, A., CORCORAN, C. et al. Fully flexible electromagnetic valve actuator: design, modelling and measurements. SAE Technical Paper 2008-01-1350. 2008. https://doi.org/10.4271/2008-01-1350

[4] DIMITROVA, D., TARI, M., LANUSSE, P. et al. Robust control for an electromagnetic actuator for a camless engine. Mechatronics. 2019, 57, 109-128.

https://doi.org/10.1016/j.mechatronics.2018.12.004
[5] FLIERL, R., GOLLASCH, D., KNECHT, A. et al. Improvements to a four-cylinder gasoline engine through the fully variable valve lift and timing system UniValve. SAE Technical Paper 2006-01-0223, 2006. https://doi.org/10.4271/2006-01-0223

[6] FRANCA, O.M. Impact of the Miller cycle in the efficiency of an FVVT engine during part load operation. SAE Technical Paper 2009-36-0081. 2009. https://doi.org/10.4271/2009-36-0081

[7] HAAS, M. UniAir - the first fully variable, electrohydraulic valve control system. 9th Schaeffler Symposium Book, 2010.

[8] HAAS, M., RAUCH, M. Electrohydraulic fully variable valve train system. MTZ - Motortechnische Zeitschrift worldwide. 2010, 71, 16-21.

https://doi.org/10.1007/BF03227946 
[9] JIAYULU, J., CHANG, S. Precise motion control of an electromagnetic valve actuator with adaptive robust compensation of combustion force. Journal of the Franklin Institute. 2019, 356(4), 1750-1770.

https://doi.org/10.1016/j.jfranklin.2018.12.010

[10] MIANZO, L., NEWTON, S., POPOVIC, Z. Integrated control and power electronics for an electromechanical valve actuation system. Proceedings of the IEEE/ASME. 2005, 485-491. https://doi.org/10.1109/AIM.2005.1511029

[11] MITIANIEC, W., BAC, G. Camless hydraulic valve timing system in combustion engines. Combustion Engines. 2011, 146(3), 28-37. https://doi.org/10.19206/CE-117089

[12] PICRON, V., POSTEL, Y., NICOT, E. et al. Electromagnetic valve actuation system: first steps toward mass production. SAE Technical Paper 2008-01-1360. 2008. https://doi.org/10.4271/2008-01-1360

[13] REINHOLZ, B.A., REINHOLZ, L., SEETHALER, R.J. Optimal trajectory operation of a cogging torque assisted motor driven valve actuator for internal combustion engines. Mechatronics. 2018, 51, 1-7.

https://doi.org/10.1016/j.mechatronics.2018.02.011

[14] SUGIMOTO, C., SAKAI, H., UMEMOTO, A. et al. Study on variable valve timing system using electromagnetic mechanism. SAE Technical Paper 2004-01-1869. 2004. https://doi.org/10.4271/2004-01-1869

[15] SCHRÖDER, C. Ein neues elektromechanisches Ventiltriebsystem von Valeo. MTZ - Motortechnische Zeitschrift. 2007, 68, 196-197.

Prof. Zbigniew Żmudka, DSc., DEng. - Faculty of Energy and Environmental Engineering, Silesian University of Technology.

e-mail: zbigniew.zmudka@polsl.pl
https://doi.org/10.1007/BF03227391

[16] SICZEK, K. The analysis of operating conditions for valves actuated by camless coupled drive. Combustion Engines. 2009, 137(2), 93-108. https://doi.org/10.19206/CE-117186

[17] SICZEK, K.J. Tribological processes in the valve train systems with lightweight valves. New research and modelling. Chapter 10 - Future valve train systems. ButterworthHeinemann, 2016, 205-219. https://doi.org/10.1016/B978-0-08-100956-7.00020-5

[18] YANG, X., LIANG, K. Measurement and modelling of a linear electromagnetic actuator driven camless valve train for spark ignition IC engines under full load condition. Mechatronics. 2021, 77, 102604.

https://doi.org/10.1016/j.mechatronics.2021.102604

[19] ZHOU, X., CHEN, Z., ZOU, P. et al. Combustion and energy balance analysis of an unthrottled gasoline engine equipped with innovative variable valvetrain. Applied Energy. 2020, 268, 115051.

https://doi.org/10.1016/j.apenergy.2020.115051

[20] ŻMUDKA, Z. Energetyczne i ekologiczne aspekty doskonalenia procesu wymiany ładunku w silniku spalinowym. Wydawnictwo Politechniki Ślaskiej, Gliwice 2010.

[21] ŻMUDKA, Z., POSTRZENIK, S., PRZYBYŁA, G. Throttleless control of SI engine load by fully flexible inlet valve actuation system. Combustion Engines. 2016, 164(1). https://doi.org/10.19206/CE-116488

Prof. Stefan Postrzednik, DSc., DEng. - Faculty of Energy and Environmental Engineering, Silesian University of Technology.

e-mail: stefan.postrzednik@polsl.pl 